\title{
POLÍTICAS LINGUÍSTICAS NA \\ UNIVERSIDADE: A PROMOÇÃO DAS LÍNGUAS INDÍGENAS NO CURSO DE LICENCIATURA EM FORMAÇÃO INTERCULTURAL PARA EDUCADORES INDÍGENAS (FIEI)
}

\author{
UNIVERSITY LINGUISTIC POLICIES: SUPPORTING INDIGENOUS LANGUAGES IN \\ AN UNDERGRADUATE INTERCULTURAL TRAINING COURSE FOR INDIGENOUS \\ EDUCATORS (FIEI)
}

POLÍTICAS LINGUÍSTICAS EN LA UNIVERSIDAD: LA PROMOCIÓN DE LAS LENGUAS INDÍGENAS EN LA LICENCIATURA FORMACIÓN INTECULTURAL PARA EDUCADORES INDÍGENAS (FIEI)

Maria Gorete Neto ${ }^{1}$

${ }^{1}$ Doutora em Linguística Aplicada pela UNICAMP. Docente do Departamento de Métodos e Técnicas de Ensino da Faculdade de Educação da Universidade Federal de Minas Gerais (UFMG), Belo Horizonte, MG, Brasil.

Resumo: Esse artigo reflete sobre as políticas linguístico-educacionais para os povos indígenas no Brasil e apresenta algumas ações de políticas linguísticas para a promoção das línguas indígenas desenvolvidas no âmbito do curso delicenciatura em Formação Intercultural para Educadores Indígenas da UFMG. No FIEI são faladas variedades de português indígena de seis povos e mais as línguas Guarani e Maxakali. Há uma preocupação bastante grande por parte do corpo docente em ensinar o português acadêmico sem sufocar as referidas línguas. Construir instrumentos do processo seletivo FIEI contemplando as línguas indígenas, facultar a expressão oral e escrita nessas línguas nas aulas e pesquisas desenvolvidas pelos universitários indígenas, desenvolver materiais didáticos e propostas de ensino são algumas das ações que vêm sendo implementadas. Espera-se que esse texto possa contribuirna reflexão e na promoção de novas ações comvistas aultrapassar algunslimitesjá detectados. Palavras-chave: Políticas linguísticas; Promoção de línguas indígenas; Ensino superior.

Abstract: This article investigates the linguistic policies for indigenous people in Brazil. It also presents some actions related to linguistic policies for indigenous students developed for the undergraduate course: Formação Intercultural para Educadores Indígenas (FIEI) [Intercultural Training for Indigenous Educators] of the Federal University of Minas Gerais, Brazil. In this course, six indigenous Portuguese languages are spoken, plus the Maxakali and Guarani languages. There is a constant concern, among the teaching faculty, to teach academic Portuguese without repressing indigenous languages. The FIEI has been constructing systems to evaluate indigenous languages, encouraging orality and writing, and developing pedagogical instruments to teach those languages. This text is intended as a contribution to the ongoing discussion. Keywords: Linguistic policies; Support indigenous languages; Undergraduate studies. 
Resumen: Este artículo refleja sobre las políticas lingüístico-educativas para los pueblos indígenas en Brasil y presenta algunas acciones de políticas lingüísticas para la promoción de las lenguas indígenas desarrolladas en el ámbito del curso de licenciatura en Formación Intercultural para Educadores Indígenas de la UFMG. En el FIEI se hablan variedades de portugués indígena de seis pueblos y más las lenguas Guaraní y Maxakali. Hay una preocupación bastante grande por parte de los maestros en enseñar el portugués académico sin sofocar las referidas lenguas. Construir instrumentos del proceso selectivo FIEI contemplando las lenguas indígenas, proporcionar la expresión oral y escrita en esas lenguas en las clases e investigaciones desarrolladas por los universitarios indígenas, desarrollar materiales didácticos y propuestas de enseñanza son algunas de las acciones que vienen siendo hechas. Se espera que este texto pueda contribuir en la reflexión y promoción de nuevas acciones con miras a superar algunos límites ya detectados. Palabras clave: Políticas lingüísticas; Promoción de las lenguas indígenas; Enseñanza en la universidad.

\section{INTRODUÇÃO}

Apesar de muitos investigadores apontarem que o Brasil é um país multilíngue (MORELLO, 2012; CAVALCANTI, 1999, RODRIGUES, 1986), há ainda, entre boa parte da população brasileira, um desconhecimento sobre a realidade sociolinguística do nosso país. Além do Português, aqui são faladas mais de 274 línguas indígenas (IBGE, 2010), Libras (Língua Brasileira de Sinais), línguas de imigrantes (Japonês, Italiano, Alemão, dentre outras), línguas de matriz africana, língua de sinais dos indígenas Urubu-Kaapor, e também inúmeras variedades de português (indígena, surdo, brasiguaios, etc.). O Português é a língua oficial do país e, recentemente, a Libras tornou-se também língua oficial dos surdos.

Também é pouco sabido que há 9 línguas cooficializadas, em 12 municípios, sendo que, destas línguas, 5 são indígenas: Nheengatu, Baniwa, Tukano em São Gabriel da Cachoeira (AM); Guarani em Tacuru (MS); Akwê Xerente em Tocantínia (TO); e 4 são línguas de migração: Pomerano em Santa Maria de Jetibá, Domingos Martins, Pancas, Laranja da Terra, Vila Pavão (ES) e Canguçu (RS); Talian em Serafina Côrrea (RS); Hunsrükisch em Antônio Carlos (SC) e Alemão em Pomerode (SC) (cf. MORELLO, 2012, p. 9). Nestes munícipios, as línguas cooficializadas são de ensino obrigatório nas escolas e todos os serviços públicos são feitos nessas línguas. A cooficialização é uma ação importante de promoção das línguas minoritárias e contrapõese à política do Estado de homogeneização linguística do país. Especialmente para os povos indígenas, cujas línguas vêm sendo sistematicamente silenciadas, torna-se imperativo elaborar políticas linguísticas públicas de reconhecimento, valorização e promoção de suas línguas, dado o papel que estas têm na construção de suas identidades (HALL, 1992).

Reconhecer, valorizar e promover línguas indígenas significa garantir a sobrevivência física e cultural dos povos indígenas, ou seja, significa assegurar a demarcação dos territórios indígenas, o acesso à saúde e à educação, o respeito aos seus direitos. Mais que garantir que tais línguas continuem sendo faladas, é necessário também ampliar e facultar seu uso em espaços socialmente prestigiados, dentre eles, a universidade. Nesse sentido, é preciso que o ambiente universitário, ao qual os povos indígenas têm tido maior acesso ultimamente, esteja minimamente preparado para esse desafio. Considerando esses aspectos, neste artigo fazse uma reflexão sobre as políticas linguísticas brasileiras e como elas têm afetado os povos 
indígenas. Apresentam-se também algumas propostas de políticas linguísticas do curso de Formação Intercultural para Educadores Indígenas (doravante FIEI), da Universidade Federal de Minas Gerais. Espera-se que a reflexão contribua para o debate sobre a promoção das línguas indígenas, em especial nos cursos de licenciatura indígena.

\section{As POLÍTICAS LINGUÍSTICO-EDUCACIONAIS BRASILEIRAS E SEUS IMPACTOS PARA OS POVOS INDÍGENAS}

As políticas linguísticas para os povos indígenas estão intrinsecamente associadas à escolarização (FERREIRA, 2000; MAHER, 2007). Até o fim da década de 70 predominou o paradigma assimilacionista que visava integrar o indígena à sociedade nacional. Posterior a essa data, surge o paradigma emancipatório que buscava fortalecer a autodeterminação indígena.

A educação escolar indígena desenvolvida até 1758 pelos jesuítas, e depois pelos outros grupos religiosos que os substituíram, insere-se no Modelo Assimilacionista de Submersão (MAHER, 2007; FERREIRA, 2000). A escola fazia parte de um conjunto de três instrumentos que visavam à assimilação indígena: aldeamento, catequese e educação. $O$ apagamento das culturas indígenas, a domesticação dos índios para servirem de mão de obra e a conversão desses povos ao cristianismo eram os objetivos norteadores desse modelo. $O$ ensino obrigatório monolíngue em português predominou nesse período e teve como consequência a desestruturação de muitos povos, o silenciamento das línguas indígenas e, em muitos casos, o extermínio de nações inteiras.

Em virtude do fracasso desse modelo educacional, foi implantado o Modelo Assimilacionista de Transição (FERREIRA, 2000; MAHER, 2007). Se antes as crianças indígenas eram retiradas da aldeia para receberem a educação escolar, agora elas recebiam escolarização dentro da aldeia. A alfabetização era feita na língua indígena nas séries iniciais e, conforme a criança familiarizava-se com a escrita, o português ia sendo introduzido até que, por fim, a língua indígena era eliminada da sala de aula. Deste modo, a língua indígena servia apenas como ponte para facilitar a transição para o português.

Com o extermínio crescente dos povos indígenas, o Estado se viu obrigado a reformular sua política indigenista, criando o Serviço de Proteção ao Índio (SPI) em 1910. A partir desse período, as escolas deveriam considerar a diversidade linguística e cultural dos povos indígenas. Agora a ênfase era colocada no trabalho agrícola e doméstico, e não mais na religião como outrora, ainda com o objetivo final da integração. Em meados de 1953, o desinteresse dos povos indígenas pela escola obrigou novamente o SPI a rever sua política educacional. As escolas passaram a ser chamadas "casa do índio", suas construções assemelhavam-se às casas indígenas, mas, substancialmente, não houve mudança, pois o objetivo da escola continuava sendo a integração e a língua de instrução continuava sendo o português.

Com a criação da Fundação Nacional do Índio (FUNAI), em 1967, entendeu-se que o ensino bilíngue seria a melhor maneira de se respeitar as comunidades indígenas. Entretanto, a proposta não vingou, pois não se priorizaram investimentos para essa ação, sob a alegação de 
que a população indígena era muito pouca. Em 1973, o Estatuto do Índio tornou obrigatório o ensino na língua indígena. A FUNAI associou-se ao SIL (Summer Institute of Linguistics ou Instituto Linguístico de Verão), ficando a cargo deste a maior parte das escolas indígenas brasileiras. Novamente não houve mudanças no fazer educação indígena, uma vez que, por trás de uma escola bilíngue de fachada, o objetivo do SIL continuava sendo integrar os índios à sociedade nacional e converter os indígenas ao cristianismo. Após grande polêmica em torno da missão evangelizadora do SIL nas comunidades indígenas, o acordo SIL-FUNAI foi desfeito em 1977 e retomado, não sem as críticas de vários acadêmicos, no início da década de 80, para ser rompido definitivamente na década de 90.

Com a efervescência do movimento indígena a partir da década de 70, a escolarização indígena começa a ganhar novos contornos. Surgem escolas indígenas alternativas, paralelas ao modelo oficial, comprometidas com a causa indígena na luta pela terra, pela saúde e pela autodeterminação destes povos. É a partir desse momento que o segundo paradigma, o Paradigma Emancipatório, pode ser observado. Dentro deste predomina o Modelo de Enriquecimento Cultural e Linguístico (FERREIRA, 2000; MAHER, 2007), que visa fortalecer as línguas nativas e promover a cultura indígena. Tanto o Português como as línguas indígenas estão contemplados no currículo escolar.

O fortalecimento do movimento indígena garantiu também grandes conquistas para os povos indígenas a partir da Constituição Federal de 1988 (CF88) que superou, no texto da lei, a perspectiva integracionista com que eram tratados. O direito de tais povos serem diferentes foi reconhecido e os índios deixaram de ser vistos como categoria transitória, ou seja, como indivíduos que, mais cedo ou mais tarde, seriam assimilados à sociedade nacional e deixariam de ser índios (cf. BRASIL/RCNEI, 1998; GRUPIONI, 2006; BERGAMASCH; DIAS DA SILVA, 2007). Além disso, o Estado passou a ser obrigado a dar condições para que estes direitos se concretizassem, conforme fixa o Artigo 231/CF88: São reconhecidos aos índios a sua organização social, costumes, línguas, crenças e tradições e os direitos originários sobre as terras que tradicionalmente ocupam, competindo à União demarcá-la, proteger e fazer respeitar todos os seus bens". É também a CF88 que fundamenta juridicamente as conquistas educacionais que vêm sendo implementadas a partir de 80. O artigo 210/CF88 assegura que a escola indígena deve atender às especificidades culturais de cada povo: "Será fixado conteúdo mínimo para o ensino fundamental, de maneira a assegurar a formação básica comum e respeito aos valores culturais e artísticos, nacionais e regionais". Com relação ao ensino de línguas, diz a CF88, Artigo 210, § 20: "O ensino fundamental regular será ministrado em língua portuguesa, assegurada às comunidades indígenas também a utilização de suas línguas e processos próprios de aprendizagem".

Como consequência desses avanços legais, o Decreto Presidencial n. 26, de 04/02/1991, retira da FUNAI a responsabilidade sobre a educação indígena e a transfere para o Ministério da Educação e Cultura (MEC). Este passa a coordenar todas as ações referentes a esse assunto, ficando a cargo das secretarias estaduais e municipais a execução das referidas ações determinadas por aquele órgão federal. A importância da federalização da educação indígena reside no fato de que muitos povos indígenas estão localizados em municípios e estados anti- 
indígenas, o que dificulta sobremaneira que os mesmos consigam fazer valer os seus direitos. A interlocução com o MEC retira poder destas instâncias menores, diminui suas influências sobre a gestão escolar indígena e torna, em certa medida, mais rápida a execução das leis favoráveis aos índios. Também em 1991, o Ministério da Justiça e da Educação assinam a portaria interministerial nº. 559/91, de 16/04/1991, criando o Conselho Nacional de Educação Indígena com o objetivo de:

Art. $1^{\circ}$ - Garantir às comunidades indígenas educação escolar básica de qualidade, laica e diferenciada, que respeite e fortaleça seus costumes, tradições, línguas, processos próprios de aprendizagem e reconheça suas organizações sociais.

Art. $2^{\circ}$ - Garantir ao índio o acesso ao conhecimento e o domínio dos códigos da sociedade nacional, assegurando-se às populações indígenas a possibilidade de defesa de seus interesses e a participação plena na vida nacional em igualdade de condições, enquanto etnias culturalmente diferenciadas.

Art. $3^{\circ}$ - Garantir o ensino bilíngue nas línguas materna e oficial do País, atendido os interesses de cada grupo indígena em particular.

Esta portaria, além de sintetizar as leis referentes à educação indígena, estabelece as condições de regulamentação das escolas indígenas e toca em pontos importantes, tais como, o calendário específico e diferenciado, a produção de material didático orientada para a realidade indígena, bem como a necessidade de construção de uma pedagogia também diferenciada e compatível com o contexto indígena (vide Art. 8 , Portaria 559/91) e ainda ressalta a importância de se formar profissionais, dentre os quais os professores indígenas, para atuar neste contexto (vide Art. $7^{\circ}$, Portaria 559/91), formação esta que o Estado deve fornecer. Por fim, vale a pena lembrar que a portaria chama a atenção para a necessidade de se garantir que os índios possam completar seus estudos dentro da aldeia e indica que o Estado tem a responsabilidade de construir e manter escolas nessas localidades.

As orientações e as obrigações do Estado descritas anteriormente são ratificadas pelos Artigos 78 e 79 da Lei de Diretrizes e Bases da Educação Nacional (LDB), de 20/12/1996, artigos estes que tratam especificamente da escola indígena no âmbito das leis para a educação a nível nacional. De acordo com o RCNEI (BRASIL, 1998, p. 33), a importância da LDB é que ela enfatiza as características que tornam a educação indígena diferente da educação não indígena, a saber, o bilinguismo e a interculturalidade, e torna possível que a escola indígena defina seu projeto político pedagógico, estabeleça a forma de funcionamento deste projeto, bem como seus objetivos e os caminhos para atingi-los. Além disso, a LDB abre brechas para que a escola atenda de fato a realidade indígena ao dizer no Artigo 26 que as escolas, em geral, devem considerar as características de cada localidade para que os objetivos do ensino fundamental sejam plenamente atendidos. Outro artigo importante da LDB, Artigo 23, flexibiliza a organização, escolar o que possibilita, no caso da escola indígena, maior flexibilidade com relação à montagem do currículo e demais elementos da vida escolar, de acordo com o que for mais conveniente para cada povo indígena. Já o Artigo 87, por sua vez, afirma que o Estado deve garantir a formação em exercício do professorado e enfatiza a necessidade de que estes profissionais sejam habilitados em nível superior. Na época de publicação da LDB, previase, inclusive, que em dez anos todos os professores devessem ter nível superior completo, condição sem a qual não poderiam ser contratados. 
Em 1998, o MEC publica o Referencial Curricular Nacional Para Escolas Indígenas (RCNEI). Fruto da interlocução com educadores, pesquisadores e assessores não índios e indígenas que já vinham atuando na prática com a educação escolar indígena, este material, como o próprio nome diz, tem o intuito de ser um referencial, um material de consulta, para subsidiar a discussão e a construção dos projetos político-pedagógicos das escolas indígenas, assim como as práticas de sala de aula, objetivando a melhoria da educação indígena e da formação de professores. Em 1999, merecem destaque o Parecer CEB/CNE 14/99 (doravante Parecer 14/99), denominado "Diretrizes Curriculares Nacionais da Educação Escolar Indígena", de 14.09.99, e a Resolução CEB/CNE 03/99 (doravante Resolução 03/99) de 10.11.99. O primeiro propõe normas para o funcionamento das escolas indígenas, para a construção de currículos e enfatiza a necessidade da educação intercultural para este contexto. O segundo fixa as Diretrizes Nacionais para o funcionamento das escolas indígenas. Um aspecto importante da Resolução 03/99 é que ela cria a categoria 'escola indígena', até então inexistente na legislação. Os artigos $1^{\circ}$ ao $5^{\circ}$ desta resolução estabelecem como deve ser a escola indígena e dá ampla autonomia aos povos indígenas para que construam esta escola de acordo com os interesses de suas comunidades (currículo, calendário, projeto político, etc.). A formação de professores indígenas é tratada nos artigos $6^{\circ}, 7^{\circ}$ e $8^{\circ}$ da Resolução 03/99. Ressalta-se a necessidade de que, para atuar na escola indígena, prioritariamente os professores sejam indígenas, bem como se enfatiza a formação específica e em serviço para a atuação nestas unidades, com a recomendação de que estes profissionais também se formem em nível superior. Os demais artigos $9^{\circ}$ ao $16^{\circ}$ descrevem e regulamentam as obrigações do Estado com relação às escolas indígenas, bem como orientam as ações dos estados e dos municípios para atender os povos indígenas neste assunto.

No ano de 2001, foi aprovada a Lei no. 10172, de 09.01.2001, denominada Plano Nacional de Educação (PNE), que dedica o capítulo 9 à educação indígena. Esta lei também ratifica o direito indígena à educação específica, diferenciada, intercultural, bilíngue, bem como reitera a necessidade de os indígenas atuarem como professores e de terem formação adequada para esta atuação. Reforça ainda a responsabilidade do Estado nesta função e no financiamento das escolas indígenas. Além disso, o PNE estabelece 21 objetivos e metas a serem atingidos na educação escolar indígena. Dentre estes objetivos figuram o reconhecimento da autonomia da escola indígena não só quanto à gestão escolar, mas também com relação à gestão financeira. Uma das referidas metas também prevê a regulamentação, a profissionalização e o reconhecimento público do magistério indígena, por meio da criação da categoria de professores indígenas. Neste caso, a necessidade de concursos específicos para a população indígena é exaltada e colocada como uma demanda a ser cumprida pelo Estado.

Com o intuito de cumprir a legislação citada e fortalecer a formação dos professores indígenas, a partir dos anos 2000 são implantadas as licenciaturas interculturais específicas para povos indígenas nas universidades. Estima-se que haja em torno de 26 licenciaturas específicas para povos indígenas atualmente. É nesse contexto que se cria o curso de licenciatura em Formação Intercultural para Educadores Indígenas (doravante FIEI) na Universidade Federal de Minas Gerais, conforme será descrito na próxima seção. 


\section{Povos indígenAs NA UNIVERSIDADE: O CURSO FIEI}

O curso de Formação Intercultural para Educadores Indígenas (FIEI) foi institucionalizado em 2008 dentro do programa REUNI na Faculdade de Educação (FaE) da Universidade Federal de Minas Gerais (UFMG). Conta com quatro turmas em funcionamento em quatro habilitações: Matemática; Ciências da Vida e da Natureza; Línguas, Artes e Literatura e Ciências Sociais e Humanidades.

O FIEI é destinado à formação de professores indígenas, que atuarão prioritariamente nas escolas das aldeias e atende à legislação atinente à consolidação da educação escolar indígena, específica, diferenciada e multilíngue, descritas anteriormente. Há 140 estudantes indígenas matriculados, de seis etnias diferentes (Guarani, Maxakali, Pataxó, Pataxó Hã Hã Hãe, Tupiniquim, Xakriabá), oriundos de cinco estados (Minas Gerais, Bahia, Espírito Santo, Rio de Janeiro e Rio Grande do Sul), distribuídos geograficamente em mais de 20 aldeias. Boa parte dos estudantes fala Português como língua materna, mas há aqueles que são falantes de línguas indígenas, tendo o Português como segunda língua.

A existência de cursos regulares de formação de professores indígenas constitui-se em uma inovação no Brasil. O FIEI teve início no "Programa das Licenciaturas Indígenas" (PROLIND) como projeto-piloto de extensão que se iniciou em 2006 na FaE. Em 2008, a consolidação dessa proposta como curso de graduação regular significou um importante passo nas relações de parceria que a UFMG vem construindo junto ao movimento indígena no sentido de garantir o direito das populações indígenas à educação e à universidade pública e gratuita. A proposta curricular é estruturada na perspectiva da interculturalidade, apresentando disciplinas relacionadas aos conhecimentos do mundo não indígena e também disciplinas e projetos de pesquisa relacionados aos conhecimentos tradicionais indígenas.

O FIEI funciona em tempos e espaços alternados, com etapas letivas nas dependências da FaE/UFMG durante cinco semanas a cada semestre letivo (os módulos) e outras nas aldeias com a presença dos professores e dos bolsistas do curso (os intermódulos). As atividades, tanto na universidade quanto nas aldeias, demandam diferentes formas de organização dos tempos e dos grupos de alunos.

A proposta pedagógica do curso e o perfil do grupo de estudantes exigem um ensino bilíngue e, portanto, um atendimento em pequenos grupos e/ou acompanhamento individual. Para tanto, a participação de estudantes de pós-graduação de diferentes unidades da universidade no desenvolvimento das atividades com os estudantes indígenas é essencial, além de constituir-se em um programa de formação para os pós-graduandos que atuam em regime de codocência. Entre as atividades que os bolsistas desenvolvem sob a orientação dos professores está a coorientação dos trabalhos de pesquisa que constituem o percurso acadêmico e estágio dos estudantes indígenas, realização de oficinas interculturais, suporte na organização dos seminários, atendimento individualizado para estudantes que apresentam dificuldades e para os falantes de língua indígena e monitoria nas aulas. Além disso, o estudante de pós-graduação bolsista no FIEI acompanha diretamente o estudante indígena, auxiliando-o na sua inserção na vida acadêmica na universidade. Ressalte-se que esse trabalho é também um importante momento de reflexão para o estudante de pós-graduação a respeito das relações interculturais que envolvem os povos indígenas, constituindo-se em uma ação importante de formação docente. 
Há também efetiva participação indígena na organização e na condução do curso. O FIEI conta com um Conselho Consultivo Indígena formado atualmente por 9 lideranças indígenas, representantes de cada povo atendido pelo curso que se reúne semestralmente. Além deste conselho, há a participação de lideranças indígenas no colegiado do curso e em comissões, como as de homologação das inscrições do vestibular e a da comissão de homologação de bolsa permanência.

Outro componente curricular são os Seminários Temáticos, nos quais são discutidas questões centrais relacionadas à educação intercultural, tais como: relações entre sociedade tradicionais e conhecimentos científicos, oralidade e escrita, tradições e traduções; a construção da educação intercultural nas políticas de educação no Brasil; as organizações indígenas no contexto brasileiro e internacional; o direito dos povos indígenas na legislação brasileira e nas resoluções internacionais; território: recursos, economia, autossustentação e conservação. Os Seminários Temáticos têm por objetivo desconstruir as lógicas de hierarquização do conhecimento e por isso contam com a presença de sábios, lideranças, pajés, xamãs e outros conhecedores indígenas na posição de professores no espaço universitário. Além disso, promovem intercâmbios técnicos e culturais entre experiências indígenas e não indígenas. Também os percursos acadêmicos dos estudantes indígenas se constituem em aspecto central do curso. Nesses percursos, desenvolvidos sob a supervisão de um docente, os estudantes indígenas realizam pesquisas com temáticas relacionadas às demandas dos territórios indígenas, originando produtos finais de formatos variados: monografias, vídeos, materiais didáticos, dentre outros.

Por fim, há que se mencionar o processo seletivo específico e diferenciado que considera os conhecimentos advindos dos territórios indígenas. A especificidade do curso FIEI, desde o seu processo seletivo, passando pela organização curricular e gestão, está fortemente amparada na legislação brasileira. Em primeiro lugar, o Artigo 78 da LDB/1996 determina que caberá ao Sistema de Ensino da União, com a colaboração das agências federais de fomento à cultura e de assistência aos índios, desenvolver programas integrados de ensino e pesquisa, para oferta de educação escolar bilíngue e intercultural aos povos indígenas, com os objetivos de:

1o) proporcionar aos índios, suas comunidades e povos, a recuperação de suas memórias históricas, a reafirmação de suas identidades étnicas e a valorização de suas línguas e ciências; 2o) garantir aos índios, suas comunidades e povos, o acesso às informações, conhecimentos técnicos e científicos da sociedade nacional e demais sociedades indígenas e não-índias.

Ao afirmar que "a União apoiará técnica e financeiramente os sistemas de ensino no provimento da educação intercultural às comunidades indígenas, desenvolvendo programas integrados de ensino e pesquisa", o Artigo 79 estabelece que as responsabilidades originárias da União devem estar compartilhadas com os demais sistemas de ensino, incluídas aqui as universidades federais, determinando procedimentos para o provimento da Educação Escolar Indígena e salientando que os programas serão planejados com audiência das comunidades indígenas, conforme indica a Convenção 169 da OIT, da qual o Brasil é signatário. Ainda de acordo com o Artigo 20, parágrafo $1^{\circ}$ do DCNEI (2012), é compromisso do Estado Brasileiro ofertar formação específica aos professores indígenas em licenciaturas específicas: 
Art. 20 Formar indígenas para serem professores e gestores das escolas indígenas deve ser uma das prioridades dos sistemas de ensino e de suas instituições formadoras, visando consolidar a Educação Escolar Indígena como um compromisso público do Estado brasileiro.

$\S 1^{\circ} \mathrm{A}$ formação inicial dos professores indígenas deve ocorrer em cursos específicos de licenciaturas e pedagogias interculturais ou complementarmente, quando for o caso, em outros cursos de licenciatura específica ou, ainda, em cursos de magistério indígena de nível médio na modalidade normal.

O parágrafo $5^{\circ}$, da mesma resolução, aponta que:

$\S 5^{\circ}$ Os sistemas de ensino e suas instituições formadoras devem garantir os meios do acesso, permanência e conclusão exitosa, por meio da elaboração de planos estratégicos diferenciados, para que os professores indígenas tenham uma formação com qualidade sociocultural, em regime de colaboração com outros órgãos de ensino.

Ao ofertar o curso FIEI, para além do cumprimento da legislação vigente, a universidade ganha a riqueza da presença indígena que, com seus saberes, suas culturas e suas línguas, oxigena o conhecimento acadêmico. Há um intercâmbio na construção de conhecimentos visando à produção de novos saberes comuns. Mas, sobretudo, esse oxigenar está atrelado ao fato de que os povos indígenas na universidade provocam a academia, deslocando certezas teóricas e pedagógicas cristalizadas, e isso sim faz a universidade se recriar. A presença deles obriga a pensar em metodologias e construções teóricas com o intuito de que o diálogo intercultural possa ocorrer.

\section{O DESAFIO DA PROMOÇÃO DAS LÍNGUAS INDÍGENAS NO FIEI}

É com o desafio de construir, ou pelo menos questionar, teorias e metodologias adotadas na universidade, que o FIEI tem lidado com as línguas indígenas no curso. É preciso esclarecer que $85 \%$ dos estudantes indígenas do FIEI falam português como primeira língua e $15 \%$ falam Guarani ou Maxakali e português como segunda língua. É comum aos dois grupos a exigência por parte da universidade de aprender o português acadêmico. Entretanto, esses dois grupos têm demandas específicas no que tange à língua: os primeiros estão também interessados em projetos de revitalização das suas línguas adormecidas, enquanto que os segundos demandam por projetos de fortalecimento de suas línguas originárias. Acrescidos a isso, há a demanda pelo fortalecimento e pela valorização do português indígena.

Falar português não significa não falar língua indígena. Primeiro, o português que esses estudantes trazem para a universidade é uma variedade de português indígena, muita distinta do português das cidades e do português acadêmico. Conforme apontam vários estudos (MAHER, 1996; D'ANGELIS et al., 2013), o português foi apropriado pelos povos indígenas que a ele deram formato e significados diferentes. O português indígena traz características próprias inerentes a cada povo que o fala. Assim, o português Xakriabá é diferente do português Pataxó e assim por diante. Estas variedades indígenas do português trazem elementos em sua estrutura e vocabulário que permitem diferenciá-las de outras variedades do português, tanto na oralidade quanto na escrita. São assim variedades importantes na construção das identidades desses povos e, portanto, são línguas indígenas.

Um desafio que tem sido posto ao FIEI é como ensinar o português acadêmico sem sufocar as variedades indígenas do português. Algumas estratégias podem ser relatadas. 
Em disciplinas como 'Produção e leitura de textos acadêmicos' e 'Estudos Orientados', os estudantes têm sido levados a refletir sobre o que é língua e os impactos desse conceito para os povos indígenas. De acordo com César e Cavalcanti (2007), o conceito língua, em sua acepção estruturalista, não serve à maior parte das realidades sociolinguísticas de muitos povos indígenas brasileiros que foram obrigados a silenciarem sua língua por força da violência do contato. Na concepção estruturalista, as línguas adormecidas são consideradas línguas extintas, o que não se coaduna com o entendimento desses povos indígenas. Assim, as autoras propõem o conceito de língua como caleidoscópio, ou seja, que a língua seja considerada em seu uso, com a carga histórica que trazem e que, por isso, é mais produtiva aos projetos de revitalização que vêm sendo implementados.

Além do debate e do estudo dessa problemática, as disciplinas também têm se ocupado de instrumentar os estudantes para a realização desses projetos de revitalização. Vários percursos acadêmicos vêm sendo orientados sobre esse tema. Além disso, os estudantes vêm produzindo vídeos e materiais didáticos e discutindo metodologias de ensino das línguas em processo de revitalização, como o Patxôhã, do povo Pataxó, a língua Akwen Xakriabá, e a língua Pataxó Hã Hã Hãe. Alguns estudantes têm escrito o seu percurso acadêmico em português mesclados às línguas em processo de revitalização (vide, por exemplo, BRAZ, 2016).

Nessas disciplinas, são também debatidas as diferenças entre o português indígena e o português acadêmico, bem como as implicações do uso de uma ou outra variedade. Para além disso, os professores do curso têm buscado valorizar os textos escritos em português indígena. Isso não significa desconsiderar equívocos gramaticais ou textos incoerentes, significa aceitar um texto que esteja estruturalmente coeso e coerente dentro dos padrões do português indígena. O FIEI também tem incentivado a manifestação de gêneros específicos do português indígena, como a loas do povo Xakriabá. A loas é um tipo de versos que os estudantes vêm utilizando para fazer seus resumos, relatórios e até percursos acadêmicos (vide LOPES, 2016).

Em se tratando dos povos que falam o português como segunda língua, o desafio tem sido maior. Em primeiro lugar, esses estudantes têm níveis de compreensão variados do português e estão imersos em turmas falantes de português como primeira língua, com professores que falam apenas português. Apesar do esforço desses docentes em adequar as aulas e os materiais didáticos aos diferentes estudantes, há sempre hiatos a serem cobertos. Uma estratégia tem sido o acompanhamento individual desses estudantes e aulas separadas por grupos linguísticos, com o intuito de que o português seja trabalhado como segunda língua, feito impossível nas turmas mistas. No que se refere às línguas Guarani e Maxakali, o FIEI não conta nesse momento com docentes falantes dessas línguas, o que limita a promoção dessas línguas, já que não é possível discutir sobre os seus processos de escrita, por exemplo. Ainda assim a esses estudantes é facultado escrever seus trabalhos e percursos acadêmicos nas suas línguas originárias (vide SOUZA, 2016). Mas isso não evita que em algum momento eles tenham que traduzir os textos para o português em virtude da limitação descrita anteriormente.

É preciso, no entanto, destacar uma ação exitosa de promoção das línguas Maxakali e Guarani no curso FIEI e que tem a ver com o processo seletivo do curso. Em 2011, os 
povos Maxakali e Guarani solicitaram sua inserção no FIEI. O processo seletivo que até então era realizado somente em língua portuguesa sofreu modificações de modo a garantir a participação desses povos. No processo seletivo 2012, os candidatos bilíngues Maxakali e Guarani puderam realizar a redação na sua língua de origem. Ainda que três candidatos Guaranis tenham obtido êxito no processo, o mesmo não se deu com os Maxakali. Assim, no processo seguinte, em 2013, a comissão de elaboração da prova do processo seletivo FIEI decidiu traduzir os enunciados para a língua Maxakali. Também não houve êxito para os Maxakali, indicando que o instrumento não estava adequado à realidade desse povo. Em 2014, novas alterações no processo seletivo foram feitas. Desta vez, seis candidatos Guarani e um Maxakali conseguiram romper a barreira do instrumento do processo seletivo.

Em 2015 e 2016 não houve candidatos Guarani, mas foram realizadas novas mudanças no processo seletivo, garantindo sala específica para candidatos Maxakali, com a presença de um intérprete Maxakali durante a prova. Entretanto, o instrumento continuou mostrando-se inadequado ao povo em questão, o que gerou um amplo debate no curso FIEI, juntamente com professores e lideranças indígenas, sobre as necessidades de uma reavaliação do processo seletivo. Em face das evidências de que o processo seletivo FIEI ainda não estava adequado ao povo Maxakali, o Conselho Consultivo Indígena do FIEI, juntamente com o colegiado FIEI, aprovou, em 2016, a realização de uma prova que fosse diferente daquela realizada pelos candidatos falantes de língua portuguesa como primeira língua.

Com base em uma experiência pregressa com o povo em questão, foi proposto um instrumento de avaliação multimodal ${ }^{1}$ e foi constituída uma banca de professores que montou, aplicou e avaliou a prova. Para a construção da prova multimodal, conforme a realidade, a língua e a cultura deste povo, alguns pressupostos teóricos foram utilizados. Em primeiro lugar, há que se considerar a realidade sociolinguística e cultural dos candidatos Maxakali na sua relação com a leitura e a escrita. Para isso, o termo letramento adquire relevância, uma vez que este conceito abarca os usos e as práticas sociais de linguagem que envolvem a escrita, de uma ou outra maneira, sejam eles valorizados ou não, globais ou locais, recobrindo contextos sociais diversos (família, igreja, trabalho, mídias, escola), em uma perspectiva sociológica, antropológica e sociocultural (ROJO, 2009, p. 98).

Esta noção também aponta a necessidade de se compreender os significados do letramento dentro de uma determinada cultura, pressupondo-se que tais significados variam por meio dos tempos e das culturas e dentro da mesma cultura (STREET, 1984; ROJO, 2009; SOARES, 1998). Logo, é uma concepção que implica a construção da cidadania, o fortalecimento das identidades, o empoderamento das culturas locais. Isso indica a necessidade de maiores e mais aprofundadas investigações sobre os letramentos locais, com o intuito de minimizar o foco ou a supervalorização do letramento escolar. Segundo Street (2003, p. 77), este posicionamento obriga a reconhecer os múltiplos letramentos e as relações intrincadas de poder que subjazem a esses letramentos. É assim que o conceito passa a ser utilizado no plural: letramentos. Essa compreensão tornou-se relevante na construção da prova Maxakali, uma vez que o instrumento proposto busca levar em conta diferentes tipos de letramento a que o povo Maxakali toma parte no seu cotidiano e não só o letramento escolar. Sem desconsiderar os letramentos locais, o 
mundo contemporâneo, altamente globalizado, tem passado por intensas mudanças associadas à intensificação e à diversificação dos usos tecnologias digitais de comunicação e de informação, com distâncias temporais e espaciais encurtadas e, por conseguinte, de mudanças nas práticas e nos usos da linguagem. De acordo com Rojo (2009, p. 105-106),

... a multissemiose ou a multiplicidade de modos de significar que as possibilidades multimidiáticas e hipermediáticas do texto eletrônico trazem para 0 ato da leitura: já não basta mais a leitura do texto verbal escrito - é preciso relacioná-lo com um conjunto de signos de outras modalidades da linguagem (imagem estática, imagem em movimento, música, fala) que o cercam, ou intercalam ou impregnam; esses textos multissemióticos extrapolaram os limites dos ambientes digitais e invadiram também os impressos (jornais, revistas, livros didáticos).

Desta forma, um desafio posto para o processo de escolarização nos diferentes níveis é tanto considerar os letramentos locais como os letramentos multissemióticos ou multimodais. Para Rojo (2009, p. 52), o papel da escola "no mundo contemporâneo é o de estabelecer a relação, a permeabilidade entre as culturas e letramentos locais/globais dos alunos e a cultura valorizada que nela circula ou pode vir a circular.". Outro desafio é formar criticamente o aluno para uma compreensão contextualizada dos usos e das práticas sociais que envolvem a escrita.

Nesse sentido, a proposta de uma prova multimodal (com sons, imagens, vídeos, desenhos, escrita, leitura e oralidade) para o povo Maxakali não só atende às necessidades específicas desse povo, mas está em consonância com a discussão mais atualizada de letramentos. Há que se dizer que esse povo tem exímios cineastas e fotógrafos, e uma relação muito peculiar com as imagens e os cantos. Logo, uma proposta de prova multimodal inclui os letramentos locais do povo Maxakali e abre, assim, uma maior possibilidade de êxito.

Além disso, dois outros conceitos subjazem à proposta dessa prova: transidioma e translinguagem. A noção de transidioma (JACQUEMET, 2016; LUCENA; NASCIMENTO, 2016) propõe que se considerem os efeitos da globalização nas práticas comunicativas. Os indivíduos têm, cada vez mais, interagido em múltiplas línguas, configurando práticas multilíngues, fortemente perpassadas por meios eletrônicos e recursos multissemióticos variados. Desta forma, adquire importância a maneira como os falantes interagem, a mobilidade dos indivíduos, que pode se dar tanto espacialmente como por meio de canais semióticos proporcionados pelas diversas tecnologias, e a "mistura" de códigos que podem ser visíveis durante o uso das línguas.

Por sua vez, translinguagem (GARCIA; WEI, 2014; LUCENA; NASCIMENTO, 2016) contempla as práticas de linguagem diversas, em contextos plurilíngues de comunicação, nas quais os indivíduos acionam estrategicamente o seu repertório linguístico. A translinguagem abarca a hibridização de primeira e segunda línguas, mas não só. Focaliza, sobretudo, como os indivíduos dão significados para o seu mundo, por meio de um processo criativo, de usar a linguagem como um conjunto de recursos móveis, que irá variar conforme o contexto social, cultural e político, na busca de que os interagentes façam sentido um para o outro. Assim, prioriza-se o fazer-se entender do indivíduo multilíngue, em detrimento de uso homogêneo de uma determinada língua.

Tanto a noção de transidioma quanto o conceito de translinguagem mostram-se adequados à especificidade Maxakali, uma vez que esse povo, além de usar a língua Maxakali, utiliza o português como segunda língua, em muitos momentos mesclando essas línguas. 
Além disso, para se fazerem entender, utilizam-se também de recursos imagéticos diversos (pinturas, imagens, sons, vídeos, dentre outros).

Ao consideraros letramentos múltiplos do povo Maxakali, o transidioma, a translinguagem, o instrumento proposto desloca o foco da avaliação nos conteúdos. As questões propostas no instrumento previam interação entre os candidatos e a banca de professores que estava aplicando o processo seletivo. A prova continha questões com imagens, com vídeos e com trechos de escrita². Todas as questões estavam em língua Maxakali e os candidatos puderam responder em Maxakali tanto na forma escrita quanto na oral. Houve também a presença de um intérprete Maxakali para facilitar a comunicação entra a banca e os candidatos. Para efeitos de avaliação e segurança, a prova foi totalmente filmada e consta nos arquivos da Comissão Permanente de Vestibular da UFMG. Além do instrumento de avaliação delineado anteriormente, o vestibular foi realizado dentro do território indígena Maxakali, o que garantiu maior tranquilidade aos candidatos Maxakali.

Com esse novo modelo de processo seletivo, que priorizou a utilização da língua e da realidade Maxakali, foram aprovados os quinze candidatos inscritos no vestibular. Esse êxito, que está associado à valorização da língua Maxakali, amplia os desafios discutidos anteriormente sobre a promoção das línguas indígenas no curso, em especial no que tange aos povos falantes de português como segunda língua. A presença de um grupo maior desses estudantes exigirá a construção de novas estratégias de acolhimento e promoção da língua em questão, mas também exigirá novas estratégias para o ensino do português a esse grupo. A utilização dos vídeos, cantos, imagens, oralidade e escrita conforme realizado na prova multimodal, associado ao trabalho individualizado com o grupo, pode ser um caminho.

\section{Considerações Finais}

Esse artigo procurou refletir sobre as políticas linguísticas para os povos indígenas no Brasil e apresentar algumas propostas de promoção das línguas indígenas desenvolvidas no curso de licenciatura em Formação Intercultural para Educadores Indígenas da UFMG.

Apesar de haver empenho e dedicação bastante grandes da equipe de docentes do curso em promover as línguas indígenas, sejam elas o português indígena, o Guarani ou Maxakali, há limites com os quais o curso se depara. Um deles é o fato de que há ainda muitas dúvidas em relação ao que é o português indígena. Os estudos sobre o português indígena só têm sido divulgados muito recentemente e muitas vezes é confundido com o falar português incorretamente (não fazer concordância nominal, verbal, cometer equívocos ortográficos, etc.). No entanto, não é disso que se trata o português indígena. Essa variedade de português traz a memória das línguas ancestrais orais, seja na estrutura, seja no vocabulário. Um texto escrito em português indígena pode apresentar recursividade, retomada do discurso conforme é realizado no texto oral, pode espelhar a estrutura da língua originária sem prejuízo ao entendimento do texto, pode trazer vocábulos especificamente utilizados pelo povo no seu território, dentre outras características. É preciso um olhar treinado e sensível para observar a ocorrência desse português indígena. Nesse sentido, é necessário que o curso realize encontros para discutir 
e estudar o português indígena para, depois de eliminadas algumas dúvidas, aprofundar a proposta de promoção dessa variedade de português no FIEI. Ressalte-se que o curso possui pelo menos seis variedades de português indígena: Xakriabá, Pataxó, Pataxó Hã Hã Hãe, Tupinikim, Maxakali e Guarani.

No que se refere às línguas Guarani e Maxakali, uma sugestão é que haja um intérprete nas aulas com o intuito de auxiliar a comunicação. Ainda assim, faz-se urgente que a equipe FIEI possa aprender pelo menos o básico dessas línguas. A promoção de uma língua se dá nas situações de uso efetivo em locais de prestígio como o é a universidade. Assim, se o docente fala a língua do estudante indígena, facilita os processos de ensino aprendizagem e a construção de conhecimentos oriundos dessa interação tão almejada pelo FIEI. Notese que a compreensão destas línguas também facilitará a compreensão da variedade de português indígena falada por estes povos. Também deverão ser reforçados os trabalhos individualizados com cada grupo linguístico em que questões específicas dessas línguas poderão ser trabalhadas. Observe-se que esses estudantes em formação deverão ensinar suas línguas nas aldeias e somente saber a língua não é suficiente para que alguém possa ensinála. Assim, o estudo das próprias línguas, a discussão de propostas de ensino e de materiais didáticos também contribuem para a promoção das referidas línguas, tanto na universidade quanto nas aldeias.

Em relação ao português acadêmico, permanece o desafio de fazer com que o estudante indígena conheça e domine as técnicas desse tipo de escrita, sem que isso contribua para o sufocamento das línguas indígenas faladas no curso. O domínio do português acadêmico e do português indígena ou do Maxakali, ou do Guarani não é excludente entre si. O estudante indígena deverá estar ciente de que o uso de uma língua em detrimento da outra tem consequências, sobretudo, políticas.

\section{REFERÊNCIAS}

BERGAMASCH, M. A.; SILVA, R. H. D. da. Educação Escolar Indígena No Brasil: Da Escola Para Índios Às Escolas Indígenas. Agora. Vol. 13, n. 1 (jan. jun. 2007). - Santa Cruz do Sul: EDUNIS, p.124-150, 2007.

BRAZ, U. C. O ensino de língua patxôhã na Escola Indígena Pataxó Barra Velha: uma proposta de material didático específico. 2016. 73 f. Trabalho de Conclusão de Curso (Licenciatura) - Faculdade de Educação, Universidade Federal de Minas Gerais, Belo Horizonte, 2016. Habilitação em Línguas, Artes e Literatura.

BRASIL. DCNEI - Diretrizes Curriculares Nacionais para a Educação Escolar Indígena Disponível em: http://portal.mec.gov.br/index.php?option=com_docman \&view=download\&alias=11074rceb005-12-pdf\&category_slug=junho-2012-pdf\& Itemid=30192. Acesso em: 09/10/17.

RCNEI - Referencial curricular nacional para as escolas indígenas. Brasília: MEC/Secretaria de educação fundamental, 1998.

Portaria Interministerial MJ/MEC No 559, DE 16.4.91. Disponível em: http://siau.edunet.sp.gov. br/ItemLise/arquivos/notas/portInter559_91.htm?Time= 1/8/2009\%207:25:15\%20AM. Acesso em: 8.10.17 
Decreto № 26, de 4 de fevereiro de 1991. Disponível em:

http://www.planalto.gov.br/ccivil_03/decreto/1990-1994/D0026.htm. Acesso em: 8.10.17.

Lei N 9.394, De 20 De Dezembro De 1996. Lei De Diretrizes E Bases Da Educação Nacional. Disponível em: http://www.planalto.gov.br/ccivil_03/Leis/ L9394.htm. Acesso em 8.10.17

LEI N 010172, DE 9 DE JANEIRO DE 2001. Plano Nacional de Educação. Disponível em: http://portal.mec.gov.br/arquivos/pdf/L10172.pdf Acesso em 29.03.18.

Constituição da República Federativa do Brasil de 1988. Disponível em: http://www. planalto.gov.br/ccivil_03/Constituicao/Constituiçao.htm. Acesso em: 10.10.17.

CAVALCANTI, M. C. Estudos sobre educação bilíngue e escolarização em contextos de minorias linguísticas no Brasil. Delta, vol. 15, nº especial, 1999, p. 385-417.

CÉSAR, A. L. S.; CAVALCANTI, M. C. Do singular para o multifacetado: o conceito de língua como caleidoscópio. In: CAVALCANTI, M. C.; BORTONI-RICARDO, S. M. (Orgs.) Transculturalidade, linguagem e educação, 2007, p. 45-66.

D'ANGELIS, W. R.; et all Ensino de Português em comunidades indígenas (1a e 2a língua). 1a. ed. Campinas, SP: Editora Curt Nimuendajú, 2013. v. 1. 1p . 168p.

FERREIRA, M. K. L. A educação escolar indígena: um diagnóstico crítico da situação no Brasil. In SILVA, A. L. da; FERREIRA, M. L. K. (Orgs.) Antropologia, história e educação: a questão indígena e a escola. São Paulo: Global, 2000, p. 71-111.

GARCIA, O.; Wei, L. Translaguaging: language, bilingualism and education. London: Palgrave, 2014.

NETO, G. M. Construindo interpretações para entrelinhas: cosmologia e identidade étnica em textos escritos em português, como segunda língua, por alunos indígenas Tapirapé. Dissertação de Mestrado PPG Linguística Aplicada, Campinas, SP: IEL/Unicamp, 2005.

GRUPIONI, L. D. B. Educação e povos indígenas: construindo uma política nacional de educação indígena. Revista Brasileira de Estudos Pedagógicos, v. 81, n. 198, maio/ago, Brasília, 2000, p. 273-283.

HALL, S. A identidade cultural na pós-modernidade. Rio de Janeiro, DP\&A Editora, 1992.

IBGE (Instituto Brasileiro de Geografia e Estatística. Censo 2010. Estudos especiais. O Brasil Indígena. Língua Falada. Disponível em https://indigenas.ibge.gov.br/ estudos- especiais-3/obrasil-indigena/lingua-falada. Acesso em: 29.03.18.

JACQUEMET, M. Transidioma. Revista da Anpoll, n 40, p. 19-32, Florianópolis, Jan./Jun., 2016.

LOPES, L. S. Loas e versos Xakriabá: tradição e oralidade. 2016. 64 f. Trabalho de Conclusão de Curso (Licenciatura) - Faculdade de Educação, Universidade Federal de Minas Gerais, Belo Horizonte, 2016. Habilitação em Línguas, Artes e Literatura.

LUCENA, M. I. P.; Nascimento, A. M. Práticas (Trans)comunicativas contemporâneas: uma discussão sobre dois conceitos fundamentais. Revista da Anpoll, n 40, p. 46-57, Florianópolis, Jan./Jun., 2016.

MAHER, T. J. M. A Educação do Entorno para a Interculturalidade e o Plurilinguismo. In: KLEIMAN, A. B.; CAVALCANTI, M. C. (orgs.) Linguística Aplicada - suas Faces e Interfaces. Campinas, SP: Mercado de Letras, 2007, p.255-270.

Ser professor sendo índio: questões de língua(gem) e identidade. 1996. 262 f. Tese (Doutorado em Linguística), Universidade Estadual de Campinas, Instituto de Estudos da Linguagem, Campinas, SP. 
MORELLO, R. A política de cooficialização de línguas no Brasil In: Colóquio Internacional de Maputo: a diversidade linguística nos países de CPLP, V. 1, N. 1, 2012, p. 8-17 Disponível em: http://www. youblisher.com/p/783318-Plato- Volume-1-N-1-Coloquio-de-Maputo-V1-2/. Acesso em: 09/10/17.

OIT (Organização Internacional do Trabalho) Convenção $n^{\circ} 169$ sobre povos indígenas e tribais e Resolução referente à ação da OIT/Organização Internacional do Trabalho. - Brasília: OIT, 2011, 1 v. Disponível em: http://www.oit.org.br/ sites/default/files/topic/gender/pub/convencao_169_ portugues_web_292.pdf Acesso em 29.03.18.

RODRIGUES, A. Línguas brasileiras - para o conhecimento das línguas indígenas. São Paulo: Loyola, 1986.

ROJO, R. Letramentos múltiplos, escola e inclusão social. São Paulo: Parábola Editorial, 2009.

SOARES, M. B. Letramento - um tema em três gêneros. Belo Horizonte, MG: Ceale/Autêntica, 1998.

SOUZA, I. de. A cestaria Guarani Mbya da aldeia Sapukai - Bracuí (RJ). 2016. 38 f. Trabalho de Conclusão de Curso (Licenciatura) - Faculdade de Educação, Universidade Federal de Minas Gerais, Belo Horizonte, 2016. Habilitação em Línguas, Artes e Literatura.

STREET, B. V. Literacy in Theory and Practice. New York: Cambridge University Press, 1984.

What's 'new' in New Literacy Studies? Critical Approaches to Literacy in Theory and Practice. Current Issues in Comparative Education, Vol. 5(2): 77-91. Columbia: Teachers College, Columbia University, 2003.

Artigo recebido em: 10/10/2017 Aprovado em: 26/03/2018

Contato para correspondência: Maria Gorete Neto. E-mail: mariagorete.neto@gmail.com

1 A elaboração da prova multimodal Maxakali foi coordenada pelos professores Vanessa Sena Tomaz e Josiley Francisco de Souza, que já tinham experiência com o processo de certificação do Ensino Médio para os Maxakali. Contribuíram em ambos os processos o professor Carlo Sandro Campos e a autora desse artigo. 